$\mathrm{C}^{8} \mathrm{H}^{14} \mathrm{O}^{2}$ besteht, haben wir nicht entscheiden können. Die erste, der Menge nach am meisten betragende Fraction lieferte bei wiederholter Destillation einen fast genau bei $208^{\circ}$ übergehenden Antheil, dessen Analysen die Formel $\mathrm{C}^{6} \mathrm{H}^{10} \mathrm{O}^{2}$ ergaben.

Die Säuren, welche in der Acrylsäurereihe mit einem Gehalt an sechs Atomen Kohlenstoff bekannt sind, sind die feste Aethylcrotonsäure, Schmelzpunkt $39,5^{\circ}$, die flüssige Hydrosorbinsäure, Siedepunkt $204,5^{0}$ und die ebenfalls flüssige Pyroterebinsäure, Siedepunkt $210^{\circ}$. Mit welcher der beiden letzteren die von uns untersuchte Säure jedoch zu identificiren ist, oder ob etwa ein Gemisch aus beiden vorlag, haben wir bei den kleinen Mengen, welche von diesen Stoffen in dem Crotonöl enthalten sind, nicht entscheiden können.

Können daher diese Angaben keinerlei Anspruch auf Vollständigkeit machen, so stellen sie es doch immerhin ausser Zweifel, dass jene Säuren nicht Glieder der Fettsäurereihe, sondern der Oelsäurereihe, deren Hauptrepräsentant die Oelsäure, sich ja, wie Schlippe nachgewiesen hat, in bedeutender Menge in Crotonöl findet.

\title{
Zur Löslichkeit von Schwefel und Phosphor.
}

\author{
Von Ir. G. Vulpius in Heidelberg.
}

Angeregt durch die Beobachtung Leo Liebermann's, dass Schwefel in concentrirter Essigsäure löslich, konnte ich schon vor einigen Monaten constatiren, dass diese Säure auch Phosphor in ziemlicher Menge aufzulösen vermag. Versuche darüber, ob auch andere Glieder der Fettsäurereihe anf die beiden genannten Elemente lösend wirken, mussten damals wegen Mangels an Zeit unterbleiben, sind nun aber wenigstens für die Ameisensäure ausgeführt worden. Dabei hat es sich grezeigt, dass die stärkste zur Verfügung stehende Ameisensäure von 1,220 spec. Gew. nur unerhebliche Mengen Schwefel aufunehmen vermochte. Bei $100^{\circ} \mathrm{C}$. waren zur Lösung von 1 Theil Schwefel 2800 Theile dieser Ameisen- 
säure erforderlich und auch diese geringe Menge aufgenommenen Schwefels scheidet sich beim Erkalten in Form eines weissen, in der dadurch milchig erscheinenden Flüssigkeit suspendirt bleibenden Pulvers nahezu vollständig wieder aus. Weniger stark macht sich beim Verdünnen mit Wasser eine Wiederausscheidung dem Auge bemerklich, vorausgesetzt, dass auch das Verdünnungsmittel gleiche Temperatur mit der Lösung hat. Ist das zugegossene Wasser kalt, so entsteht eine sehr starke milchige Trübung; man würde jedoch irren, dieselbe auf Rechnung der Verdünnung zu schreiben, sie ist der Hauptsache nach ein Effect der Abkühlung. Es findet also für die Lösung des Schwefels in Ameisensäure das Umgekehrte statt wie bei der Lösung des Phosphors in Essigsäure; hier tritt durch Verdünnung der heissgesättigten Lösung mit Wasser eine starke, beim Abkühlen eine sehr geringe Wiederausscheidung des gelösten Körpers ein, während dort beim Erkalten eine bedentende, beim Verdünnen mit Wasser dagegen nur eine schwache Ausscheidung beobachtet wird. Ist schon die Löslichkeit des Schwefels in Ameisensäure eine so geringe, so wird die des Phosphors in der nämlichen Säure als eine spurweise zu bezeichnen sein. Lässt man erwärmte Ameisensäure stundenlang auf Phosphor einwirken, so resultirt zwar eine Fluissigkeit, welche auf Wasserzusatz sich ganz wenig trübt, aber beim Erkalten klar bleibt und an der Luft im Dunkeln kaum phosphorescirt. Ihr Gehalt an Phosphor dürfte ein Zehntausendstel schwerlich übersteigen.

Es wird nun durch Versuche mit Propionsäure, Buttersüure u. s. w. zu ermitteln sein, ob alle Glieder dieser Säurereihe ein gewisses Lösungsvermögen für Schwefel und Phosphor besitzen. Für diese Annahme spricht ausser dem Verhalten von Ameisensäure und Essigsäure die Thatsache, dass ein einzelnes höheres Homologon, die Stearinsäure, in höherer Temperatur bedeutende Mengen von Schwefel und nicht unerheblich Phosphor aufzunehmen vermag. Diese Lösungen können ihrerseits in warmem Alkohol aufgenommen werden, ohne dass eine Wiederabscheidung des gelöst gewesenen Schwefels 
oder Phosphors sich bemerklich macht. Man könnte also auf diesem Wege, da die alkoholische Lösung der phosphorhaltigen Stearinsäure beim Erkalten gelatinirt, eine opodeldocartige Anwendungsform des Phosphors sich verschaffen.

\title{
Ueber mechanische Reinigung von Quecksilber.
}

\author{
Von Demselben.
}

Bei Absperrung von Gasen über Quecksilber und den damit verbundenen Manipulationen wird das letztere nach wiederholtem Gebrauch sehr bald an der Oberfläche schmutzig und dadurch in vielen Fällen für den gleichen Zweck unbrauchbar. So wurden uns von dem hiesigen pathologisch-anatomischen Institut mehrmals grössere Mengen von stark verunreinigtem Quecksilber mit der Bitte ïbergeben, dessen Reinigung in einfacher Weise zu versuchen. Waschen mit Wasser, Alkohol, Aether und nachheriges Trocknen mit Filtrirpapier erfüllte den Zweck nur sehr unvollkommen, weil, wenn auch der Schmutz entfernt war, an seiner Stelle nunmehr zahlreiche Papierfäserchen den Spiegel der Oberfläche trübten. Dagegen kommt man in überraschend einfacher Weise zum Ziele, wenn man den untersten Theil eines kleinen trockenen Faltenfilters aus starkem Papier etwa zehnfach mit einer recht groben Nadel durchlöchert, dasselbe in einen entsprechenden Trichter bringt und das Quecksilber aufgiesst. Solange das Filter ziemlich voll, der Druck also stark ist, rinnt das Quecksilber in blanken Tropfen von selbst in den untergestellten Behälter, später muss das Abfliessen durch Ruitteln unterstiitzt werden, bis etwa noch 1-2 Procent des Quecksilbers auf dem Filter sich befinden. Auf diesem Reste, sowie an den Filterwänden hat sich alsdann sämmtlicher Schmutz der ganzen Quecksilbermenge gesammelt und wird sich eine anderweitige Verwerthung oder Verarbeitung dieser kleinen Verlustmenge wohl stets ergeben, während die Hauptmasse des Metalls jetzt wieder tadellos blank und zu jedem Zwecke tauglich erscheint. 